parotid became inflamed. The seven weeks that elapsed between the commencement of the symptoms of parotitis in the two cases is certainly a greater length of time than usual, but I think one can hardly exclude infection from the first case as a cause of the second case. When considered with Dr. Addenbrooke's cases these cases are interesting, as in them the opposite condition from that found in those of Dr. Addenbrooke obtained-viz., there was a case of infective parotitis in the same house seven weeks before the onset of double parotitis following an abdominal wound, whilst in Dr. Addenbrooke's cases a double parotitis followed an abdominal section, and after coming in contact with the patient inflammation was set up in the second person's parotids. 'This second person again apparently infected a third person. $A s$ it is, I think, doubtful whether my second case was a case of true mumps or parotitis following an abdominal wound, so I think it must also be doubtful whether Dr. Addenbrooke's first case was one of parotitis caused by the abdominal wound or a case of true mumps due to infection the source of which he was unable to trace; just as in my first case of mumps I was unable to trace the source of the infection.

Leith, N.B.

\section{A CASE OF GANGRENE OF THE PENIS.} BY GEORGE A. OLARKSON, F.R.C.S. ENG.

GANGRENE of the penis occurring as a complication of any illness is necessarily of extreme rarity and has only been known to occur in conditions of great vital depression. It is mentioned as occurring occasionally in cases of typhus fever and it has been known to follow paraplegia. However, very few cases have been described and most surgical works do not even refer to it. In the present instance a feeble and dilated heart, extensive atheroma of the arteries, possibly inoculation of some part of the urethra with infective organisms, were the determining factors.

The patient, aged 51 years, employed in an iron foundry, had suffered severely from chronic bronchitis every winter for 15 years. For some years he had only been able to work in the summer months and latterly had so lost ground that he had been obliged to give up work even then. He emaciated considerably; his aspect became yellow and cadaverous, cough and expectoration were constant, and there was more or less complete loss of appetite and also some cedema of the legs. Examination of the chest revealed much emphysema, exceedingly feeble and distant heart sounds, and a slight impulse outside the nipple line; no murmur was audible. The temporal and radial arteries were very tortuous and rigid and the pulse was feeble and intermittent. In this condition he remained till Sept. 28th, 1899, when he suddenly became very faint and collapsed. He was put to bed and wrapped in blankets. When seen he was barely conscious, the extremities were cold, the heart sounds were inaudible, and the pulse was hardly perceptible. With cardiac and general stimulants he rallied and seemed to be better for some days. The tongue, however, remained coated and dry, there was some mattering delirium at night, and the urine, which had been ammoniacal and offensive, became more so now that he was confined to bed. On Oct. 11th he complained of considerable pain in the penis, which was much swollen all over. There was no phimosis or sore under the prepuce. On the 13th several gangrenous patches appeared and during the next day or two the whole organ became involved. Five incisions were made deep into the tissues with the view of relieving any possible tension, but there did not appear to be any; the deeper parts of the organ seemed to be equally affected and only a small quantity of dark fluid was discharged into the dressings. The whole organ appeared to be in a condition of ordinary moist gangrene. Owing to his general condition no further operative measures were deemed advisable. Continuous hot boric fomentations were applied and immersion was given in a hot boric bath; opium, carbonate of ammonia, and digitalis were given internally. The patient died on Oct. 16th, the whole organ being completely gangrenous.

It seems hardly credible that an organ with the anatomical peculiarities of the penis could be the subject of dry gangrene, yet such has occurred. In the case of a patient under the care of the late Mr. Partridge at King's College Hospital ${ }^{1}$ gangrene attacked the penis and the organ became black and charred-looking. A line of demarcation formed, urine issued at this point, the penis dropped off, and the patient made a good recovery. His age was only 40 years. Leicester.

\section{A mitror}

\section{HOSPITAL PRACTICE, BRITISH AND FOREIGN.}

Nulla antem est alia pro certo noscendi via, nisl quam plurimss et morborum et dissectionum historias, tum aliorum tim proprias Morb., lib. iv. Procemium.

\section{ST. THOMAS'S HOSPITAL}

TWO CASES OF SARCOMA OF THE BI EAST.

(Under the care of Mr. W. H. BATT LE.)

TraumatisM as an etiological factor in th appearance of sarcoma is now generally accepted, although it is not possible to offer any very satisfactory explanation of the manner in which an injury gives rise to the new growth. In many cases the sarcoma appears before the swelling caused by hæmorrhage or inflammation has completely subsided, and it is possible that these effused products form a suitable nidus for the development of the neoplasm. True sarcomata of the breast are certainly not common, and the two interesting cases recorded below are in many ways noteworthy ; especially remarkable is the age of the patient in the second case-namely, 13 years.

CASE 1.-A woman, aged 36 years, was admitted into St. Thomas's Hospital on June 8th, 1900, complaining of a tumour of the breast. About 14 months before admission she had received a blow on the left breast, which became tender and was much bruised. Soon after this she suffered from a sharp pain in that breast, worse in damp weather, and she also noticed that a swelling was present. She therefore consulted a medical man who prescribed some medicine. The swelling in the breast grew steadily larger and she took to her bed. About ten days before admission the patient got up and had a severe bæmorrhage from the breast and therefore bad to take to her ${ }^{x}$ bed again. After this she was so weak that she fainted whenever she sat up. A week before admission the breast began to fungate and then grew rapidly. The only point in her family history of any importance was the statement that an aunt on the mother's side had had "cancer of the breast" for a year and was still alive.

On admission the patient was very thin and anæmic and had an anxious expression. The left breast was the seat of a large musbroom-like fungating tumour with an offensive, thin, bloody discharge (see figure). The tumour was flattened, with a margin which was much everted. The breast itself was not much enlarged and formed a kind of pedicle for the expanded part; this pedicle was narrower from within outwards than from above downwards. The surface of the tumour was nodular and blackened. In the left axilla one enlarged gland could be felt. The other organs were quite normal.

On June 11th Mr. Battle operated. The narrowness of the attached portion of the breast already mentioned was utilised; it was clamped like a pedicle with two long-bladed forceps passed from above and from below in the line of the pectoralis major. The growth was cut away close to the forceps and the breast was then excised. The axillary gland was not touched, as its enlargement was supposed to be due to septic absorption from the surface of the tumour. Very little blood was lost during the operation and this was so thin and pale that it produced merely yellow staining of the aseptic cloths which surrounded the operation area. There was apparently no tendency to infiltrate the breast substance-in fact, the breast itself appeared to be quite small and really not much larger than the opposite one. 